\section{Y-12}

\section{OAK}

RIDGE

$\mathrm{Y}-12$

PLANT

UNION CARBIDE
DIAMOND-TURNING TOOL SETTING BY INTERFEROGRAM ANALYSIS

\author{
W. H. Rasnick \\ R. C. Yoder
}




\section{DISCLAIMER}

This report was prepared as an account of work sponsored by an agency of the United States Government. Neither the United States Government nor any agency Thereof, nor any of their employees, makes any warranty, express or implied, or assumes any legal liability or responsibility for the accuracy, completeness, or usefulness of any information, apparatus, product, or process disclosed, or represents that its use would not infringe privately owned rights. Reference herein to any specific commercial product, process, or service by trade name, trademark, manufacturer, or otherwise does not necessarily constitute or imply its endorsement, recommendation, or favoring by the United States Government or any agency thereof. The views and opinions of authors expressed herein do not necessarily state or reflect those of the United States Government or any agency thereof. 


\section{DISCLAIMER}

Portions of this document may be illegible in electronic image products. Images are produced from the best available original document. 
Printed in the United States of America Available from

National Technical Information Service

U. S. Department of Commerce

5285 Port Royal Road

Springfield, VA 22161

NTIS price codes

Printed copy: A02

Microfiche copy: A01

\section{DISCLAIMER}

This report was prepared as an account of work sponsored by an agency of the United States Government. Neither the United States Government nor any agency thereof, nor any of their employees, makes any warranty, express or implied, or assumes any legal liability or responsibility for the accuracy, completeness, or usefulness of any information, apparatus, product, or process disclosed, or represents that its use would not infringe privately owned rights. Reference herein to any specific commercial product, process, or service by trade name, trademark, manufacturer, or otherwise, does not necessarily constitute or imply its endorsement, recommendation, or favoring by the United States Government or any agency thereof. The views and opinions of authors expressed herein do not necessarily state or reflect those of the United States Government or any agency thereof. 
Date of Issue: October 22, 1980

Distribution Category: UC-38

\title{
DIAMOND-TURNING TOOL SETTING BY INTERFEROGRAM ANALYSIS
}

\author{
W. H. Rasnick \\ R. C. Yoder
}

Fabrication Systems Department

Y-12 Development Division

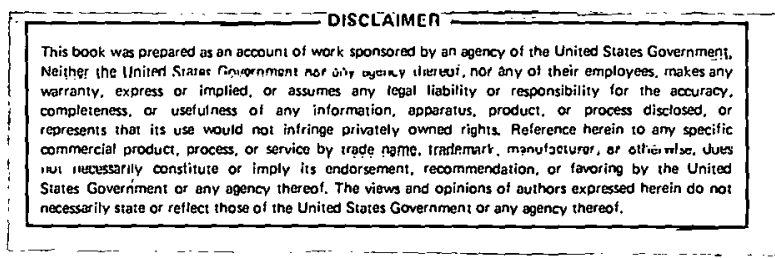

Oak Ridge Y-12 Plant

P. O. Box Y, Oak Ridge, Tennessee 37830

Prenated lü the Dejairliment of Energy Under US Government Contract W-7405-eng-26

DISTRIBUTION OF THIS OOCUREET IS UELLIARTED 


\begin{abstract}
A method has been developed to establish a numerically controlled tool path with respect to the work spindle centerline. Particularly adapted to the diamond turning of optics; this method is based upon interferogram analysis and is applicable to the establishment of the work spindle centerline relative to the tool path for any center-turned optic having a well-defined vertex radius of curvature. The application reported is for an $f / 2$ concave spherical mirror.
\end{abstract}




\section{CONTENTS}

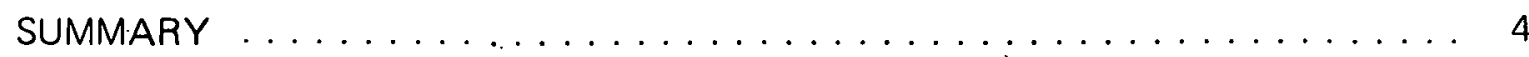

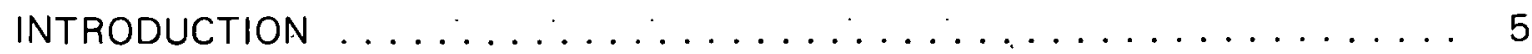

DIAMOND-TURNING TOOL SETTING BY INTERFEROGRAM ANALYSIS . . . . . 6

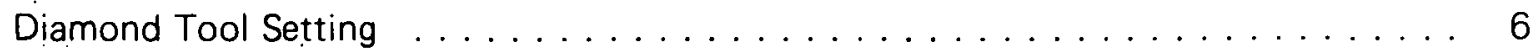

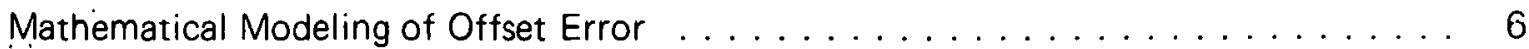

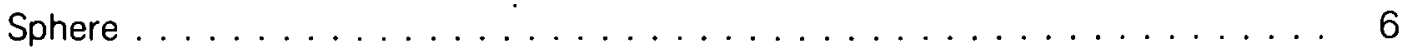

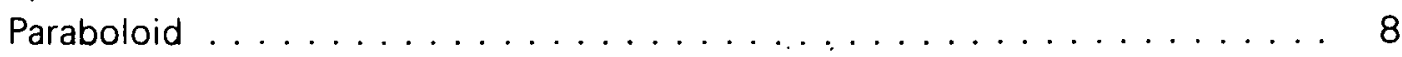

Simplified Derivation and Calculation $\ldots \ldots \ldots \ldots \ldots \ldots$

General Considerations . . . . . . . . . . . . . . . . . . . . . . . . . . 11

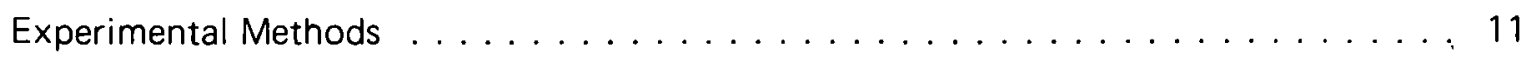

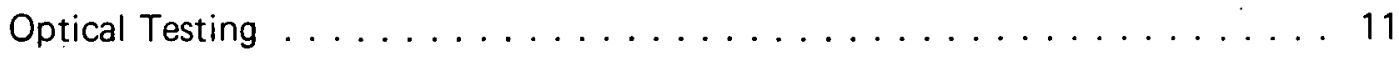

Calculation of Offset $\ldots \ldots \ldots \ldots \ldots \ldots \ldots \ldots \ldots$

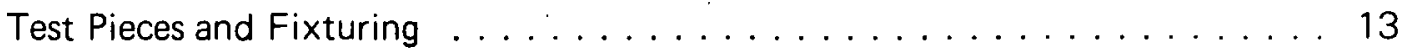

Experimental Results ........................ 13

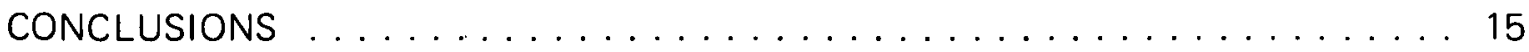

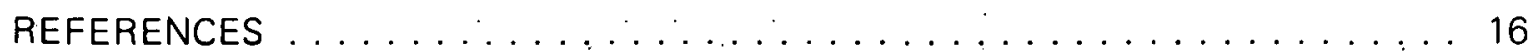

ACKNOWLEDGMENTS ......................... 17

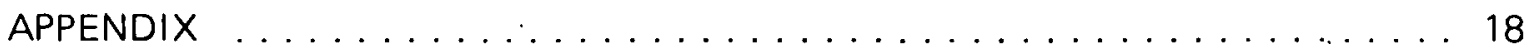

Derivation of Three-Point, Best Fit, True Radius $\ldots \ldots \ldots \ldots \ldots \ldots$ 


\section{SUMMARY}

A method for diamond-turned optics has been developed to establish the starting point of a numerically controlled (NC) tool path with respect to the work spindle centerline. Particularly adapted for concave and center-turned optics, this method is based on an interferometric analysis which quantifies an artifact that is linearly related to tool offset.

Unless a tool is perfectly set, the resultant part shape near the center of the part resembles a bullet or a heart, depending on the direction of the offset of the tool path from its correct position. An interferogram of a turned part can be analyzed to determine this offset error. For the special case of an $f / 2$ mirror, the tool offset was analyzed in this manner and the results were used to make an improved cut.

The major advantage of this method over a linear variable-differential transformer (LVDT) tool setter or over machining and measuring a diameter is that the actual cutting portion of the tool is set with respect to the spindle centerline. Because of this, large- (1/8-in or $3 / 16$-in) radii diamond tools which have insufficient arcs for diametral tool settings can be accurately positioned. Accuracy of this method is better than $1 \mu \mathrm{m}(40 \mu \mathrm{in})$ for an $\mathrm{f} / 2$ spherical reference surface. 


\section{INTRODUCTION}

With the advent of numerically controlled turning machines came various methods of relating the NC contour to the machine-spindle face and centerline. All these methods fall under the general classification of tool setting. Basically, tool setting has been done by using one of three different methods: (1) establishing a stationary tool set station within the range of machine travel but beyond the limit of actual machining, (2) touching up with shim stock from a known diameter and face, or (3) machining and measuring a diameter and face. Various mechanisms have been employed in the first method (LVDT, ${ }^{1}$ spark-gap, ${ }^{2}$ and ball contact ${ }^{3}$ ) for actually locating the tool with respect to the machine's axes. In most production applications on $x-y$ turning machines at the Oak Ridge $Y-12$ Plant, (a) the first method has been used and even automated. The second and third methods may be applicable in special cases where it is not feasible to develop the necessary hardware and software to establish a tool set station.

Tools must contain a sufficient arc to allow setting in two orthogonal axes, and many tools used in diamond turning do not have enough arc to be set at a known diameter. Although a tool may have sufficient arc to fabricate $f / 1$ parabolic optics, it can be accurately set only in the $y$-direction which, in most cases, is not as critical as the tool position in the $x$-direction. Tool offset in the z-aperture dimension can readily be seen to display no significant optical effect except within a very small neighborhood of the spindle axis and, hence, is not considered here. To solve the problem, a method of tool setting based on an analysis of the interferogram of a turned $f / 2$ spherical mirror is presented here. A description of hardware and an example of an actual application are given with the expressed purpose of providing useful information to the diamond-turning industry.

(a) Operated by the Union Carbide Conrnoration's Nuclear Division for the Department of Energy. 


\section{DIAMOND-TURNING TOOL SETTING BY INTERFEROGRAM ANALYSIS}

\section{DIAMOND TOOL SETTING}

The tool setting requirement (Figure 1) and a profile of commonly used tools (Figure 2) show the need for setting a tool to accommodate two orthogonal axes. Three approaches were considered: (1) establish a feature on the tool shank that can be set in the $x$-direction, (2) use smaller radii diamond tools which have $100^{\circ}$ of arc, and (3) develop a method of locating the edge of the existing tool in the $x$-direction via interferometric analysis of turned optics.

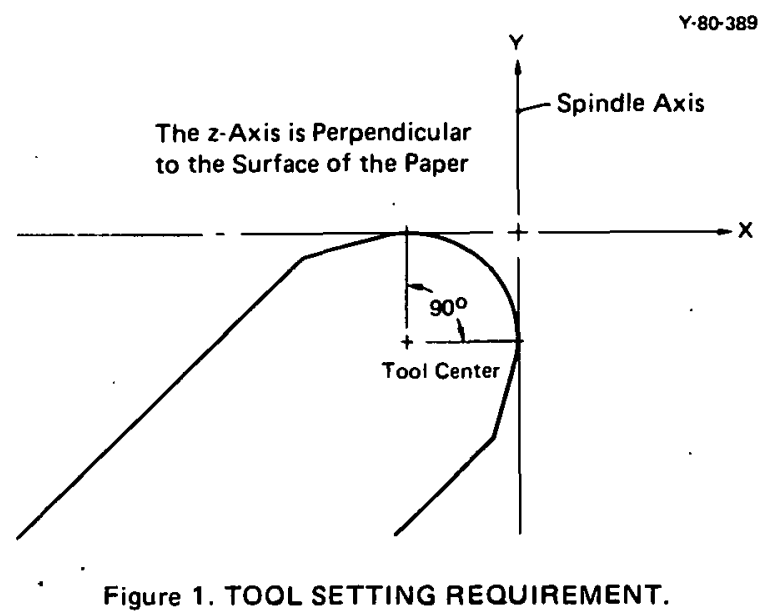

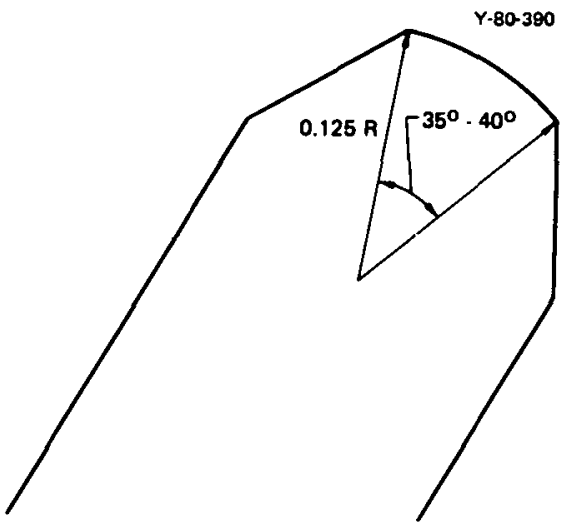

Figure 2. TYPICAL'DIAMOND-TURNING TOOL PROFILE.

A locating feature on the tool shank would increase the original cost of the diamond tool, would be difficult to inspect and certify, and could change position when the tool is resharpened. A smaller radius diamond tool, with a typically 0.021 -in or 0.032 -in radius, could have a localized edge defect in the $x$-axis direction which could establish an erroneous tool set point. Also, the smaller tools require a slower feed rate than the larger radii tools to obtain a comparable surface finish. Therefore, the third option was explored. With an interferogram analysis of the diamond-turned part, $Y-12$ personnel have determined the tool path offset which enables the operator to correctly position a turning tool with respect to its spindle centerline.

\section{MATHEMATICAL MODELING OF OFFSET ERROR}

\section{Sphere}

An offset error in the presence of an otherwise correct tool path lassuming that there exists no misalignment of the spindle axis that could generate a like error) can be seen to generate an error which, to lowest order, is a simple linear cone (Figure 3). In real space, a perfect but off-center tool path is described by:

$$
\mathrm{X}_{1}^{2}+\mathrm{Y}^{2} \doteq \mathrm{R}_{1}^{2}=\text { constant. }
$$


With an offset, $X_{0}$, this curve must be transformed in terms of a coordinate $(X)$ from the turning (and inspection) center point defined by:

$$
x=x_{1}+x_{0}
$$

The surface generated is then:

$$
\begin{aligned}
& R^{2}=x^{2}+y^{2}=R_{1}^{2}+2 x x_{0}+x_{0}^{2}, \text { and } \\
& R=R_{1}\left[1+\frac{2 x x_{0}+x_{0}^{2}}{R_{1}^{2}}\right]^{1 / 2}
\end{aligned}
$$

Given that $X_{0}<<R_{1}$ and that $X / R_{1} \cong \sin \rho+X_{0} / R_{1} \sin ^{2} \rho$ (from Figure 3), Equation (1) may be expanded thus:

$$
\begin{aligned}
& R \cong R_{1}\left[1+\frac{\left(x x_{0}+1 / 2 x_{0}^{2}\right)}{R_{1}^{2}}-\frac{\left(2 x x_{0}+x_{0}^{2}\right)^{2}}{8 R_{1}^{4}}+\ldots\right] \\
& R-R_{1} \cong\left[\left(x_{0}\right) \sin (\rho)+\left(\frac{x_{0}^{2}}{2 R_{1}}\right) \sin ^{2}(\rho)-\left(\frac{x_{0}^{3}}{2 R_{1}^{2}}\right) \sin (\rho)+\ldots .+ \text { constant }\right] \\
& \cong x_{0}\left[1-\frac{\left(X_{0}\right)^{2}}{2 R_{1}^{2}}+\ldots\right] \sin (\rho)+\frac{X_{0}^{2}}{2 R_{1}}[1+\ldots] \sin ^{2}(\rho)+ \\
& \text {... + constant. }
\end{aligned}
$$

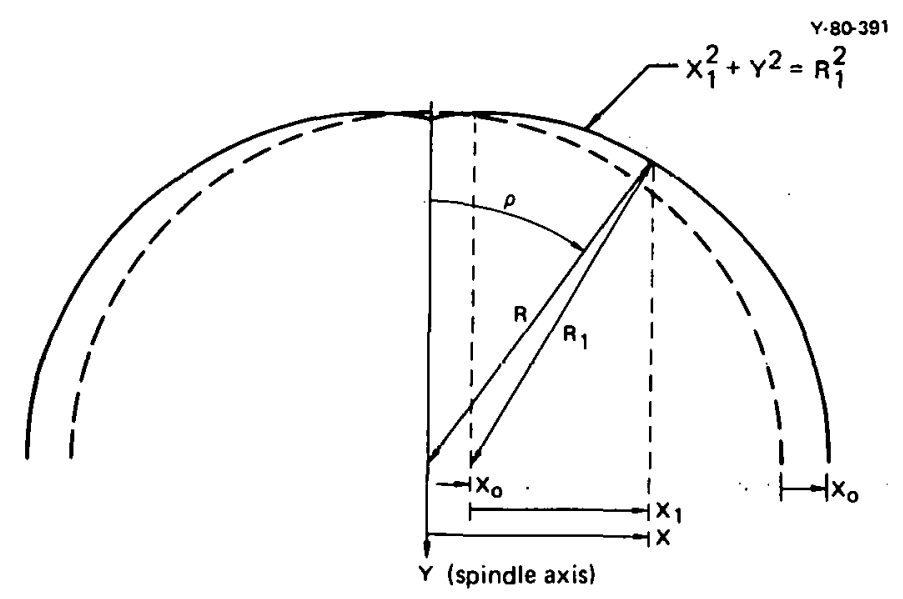

Figure 3. OFFSET ERROR MODEL FOR SPHERE. 
For reasonable tool-setting accuracies and for reasonable optic apertures:

$$
\left|x_{0}\right| / R_{1}<\sin \rho<1 .
$$

Therefore, dropping all but the lowest degree term in $X_{0}$ in Equation (2), a surface deformation (with the sign convention with which interferograms are usually read) will result of the form:

$$
R_{1}-R \cong-X_{0} \sin \rho=n \lambda / 2
$$

where $n$ would be the number of fringes of this term in an interferogram taken of this surface in a dual-beam Twyman-Green test at some wavelength $(\lambda)$ used for inspection.

Thus, both the magnitude and the sign of the tool offset can be read directly from the amount of linear cone seen in the interferogram so long as the object plane (located at the spherical mirror) is mapped linearly into the radial coordinate at the interferogram plane. This mapping normally is linear to at least a good approximation, particularly for the relatively small numerical apertures $(\rho<<1)$ normally in view. For an $f / 2$ diverger centered on the part axis, the maximum polar angle in view (in a centered view) is 0.25 radian.

\section{Paraboloid}

Of special interest here (although not done experimentally in this investigation) is the case of tool offset analysis applied to a centered paraboloid. As in Figure 4, the surface generated is:

$$
X_{1}^{2}=4 f Y_{1}
$$

as opposed to the intended path:

$$
X^{2}=4 f Y .
$$

Relative to an optical inspection point located at the focus:

$$
\begin{aligned}
\rho & \cong \cos ^{-1}\left[\sqrt{(\dot{f}-Y)^{2}+X^{2}}\right] \\
& =\cos ^{-1}\left[\sqrt{\left(4 f^{2}-X^{2}\right)}\right] \\
& =\cos ^{-1}\left[\frac{\left.4 f^{2}-X^{2}-X^{2}\right)^{2}+(4 f X)^{2}}{4 f^{2}+X^{2}}\right]
\end{aligned}
$$

and the angle of incidence (again in a standard Twyman-Green test) is $\rho / 2$. Whenever $X_{0}<<f$, the approximation $\left(\rho_{1} \cong \rho\right)$ is certainly good enough to allow the substitution $\left(\rho_{1}\right.$ for $\left.\rho\right)$ in Equation (5). Once again, suppose that the tool is offset a small amount, $X_{0}$, from the spindle axis and the optic therefore is inspected relative to the coordinate,

$$
x=x_{1}+x_{0} \text {. }
$$




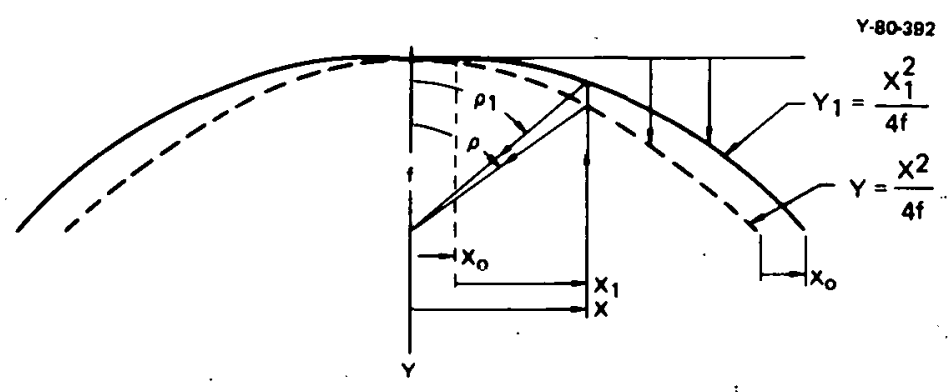

Figure 4. OFFSET ERROR MODEL FOR PARABOLOID.

sn that the displaced (although otherwise perfect) surface that has been cut becomes by Equation (4):

$$
4 f Y_{1}=x_{1}^{2}=x^{2}-2 X x_{0}+x_{0}^{2}=4 f Y-2 X x_{0}+x_{0}^{2}
$$

The induced optical path difference (OPD) will be:

$$
\begin{aligned}
& O P D \cong\left(Y_{1}-Y\right)(1+\cos \rho)=\frac{-2 X X_{0}+X_{0}^{2}}{2 f} \cos ^{2}(\rho / 2) \\
& O P D \cong \frac{-X X_{0}}{f} \cos ^{2}(\rho / 2)=\frac{-X X_{0}}{f} \sqrt{\frac{1+\cos \rho}{2}} \cos (\rho / 2)
\end{aligned}
$$

From Equation (5). this becomes:

$$
\begin{aligned}
O P D & \cong \frac{-x x_{0}}{f} \sqrt{\frac{1+\frac{4 f^{2}-x^{2}}{4 f^{2}+x^{2}}}{2}} \cos (\rho / 2) \\
& =-2 x_{0} \sqrt{\frac{x^{2}}{4 f^{2}+x^{2}}} \cos (\rho / 2) \\
& =-2 x_{0} \sqrt{\frac{1}{2}-\frac{\cos \rho}{2}} \cos (\rho / 2) \\
& =-2 x_{0} \sin (\rho / 2) \cos (\rho / 2)=-x_{0} \sin \rho=m \lambda,
\end{aligned}
$$

where: $m=$ the number of fringes and

$\lambda=$ the wavelength used for inspection.

Note that this is the exact result derived in Equation (3) for a sphere inspected at its center of curvature. Equation (3) is given in terms of surface contour, rather than OPD (and 
is equal to one-half of the OPD for that case). Hence, there is an apparent difference in results.

For an off-axis section of a paraboloid, this development would be applicable to the centered coordinate system of the "mother" parabola and not to the local coordinate system of the particular off-axis section. It is easily seen, however, that this "centered" linear cone will principally generate a local astigmatic contribution, in an off-axis section of the aperture; and this, in turn, can be reduced at will through the test path alignment. However, it should be noted that both astigmatism and other induced terms (such as coma) cannot be simultaneously compensated through test alignment.

\section{Simplified Derivation and Calculation}

Ideally, on an NC-generated spherical contour, the tool will stop its cutting path exactly at the spindle centerline. If the path is offset with respect to the centerline, the resultant shape near the center of the part resembles a bullet or a heart, depending on the direction of offset of the tool path. Figure 5 shows the two cases. Note in Figure 5(a) that the zero or reference surface is the lowest point; conversely, in Figure 5(b), the reference surface is the highest point. The number of fringes to the edge times the contour level value of each fringe is the deviation from the reference spherical contour. Figure 6 shows the diagram and a simple derivation of the equation with which to calculate tool offset. The number of fringes, $K$, counted in this manner will include both tilt and linear cone in equal amounts and, therefore, will be equal to twice the number of fringe orders of pure cone, $n$, as in the preceding development. This renders an interferogram which is easily interpreted, visually. Although the derivation shown is for a bullet, it is valid also for a heart surface and for convex as well as concave surfaces; however in this latter case, there will be a change in sign.

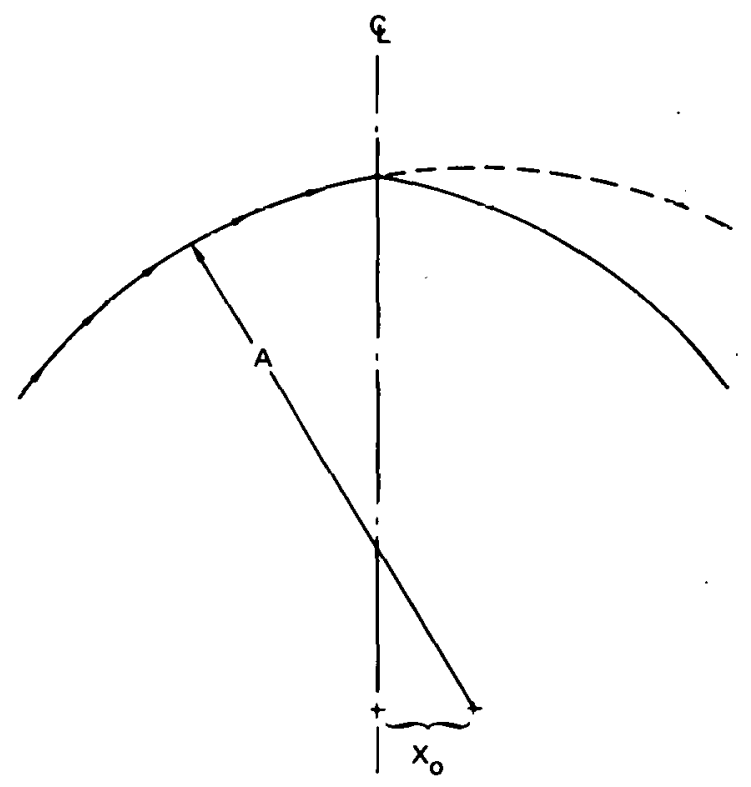

(a) Tool offset past centerline producing a bullet.

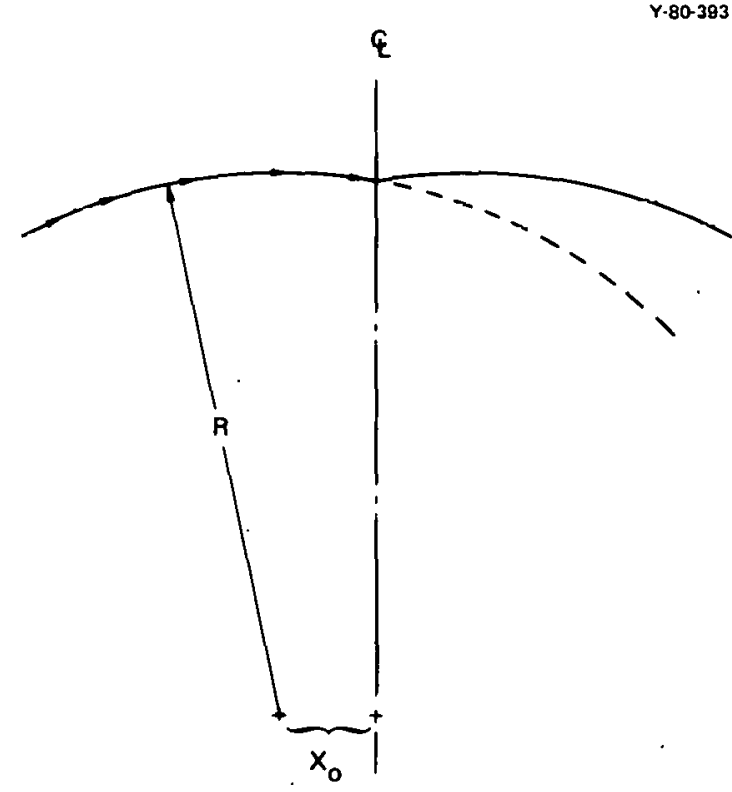

(b) Tool offset short of centerline producing a heart.

Figure 5. EXAGGERATED EFFECTS OF TOOL OFFSET ON TURNED SPHERICAL SURFACE. 
General Considerations

It should be noted that this optical tool-setting technique is applicable, in general, to the machining of any surface having a well-defined and nonvanishing vertex radius of curvature, since the leading (cone) error is dependent upon the second-order relief (from flatness) only and not upon any higher order terms which delem mine thal sur face. The departure from the linear conic error, to be expected at wide apertures, is determined by those higher order terms and the varying angle of incidence for the optic test under consideration.

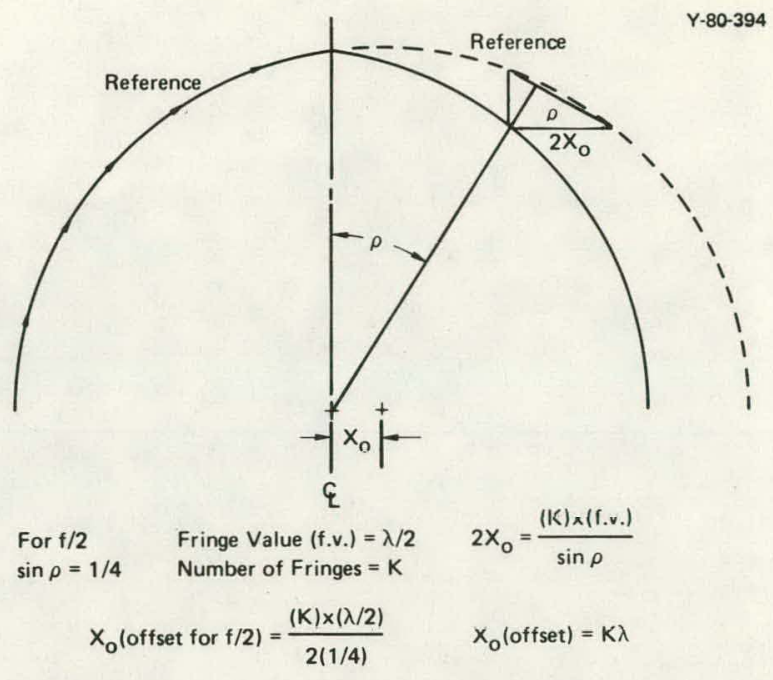

Figure 6. CALCULATION OF TOOL OFFSET.

\section{EXPERIMENTAL METHODS}

\section{Optical Testing}

All interferometric data were gathered with a laser unequal-path interferometer (LUPI). Reference 4 provides an excellent presentation on the basics of interferometric contour testing. To inspect for tool offset, a test for a concave spherical mirror was conducted as outlined in this reference; and minor focus and tilt adjustments were made to enhance the perception of the desired results. Figure 7 shows the experimental setup with the mirror and the interferometer.

In general, a focal error can be superimposed upon the linear cone along with an arbitrary tilt in two dimensions. Focal adjustments of the interferometer can be made by translation along the spindle axis, adjusting tilt via the other two axes until the test and reference wave fronts attain a condition of tangency. In the absence of tool path errors, the tool offset error will produce a wedge (arrowhead-shaped zero) or tangent fringe.

The smaller the tool offset error, the wider will be the angular spread of the tangent fringe. In Figure 8, Views (a) and (b) show interferograms of two cuts with such a pattern. Deviation of the side boundaries of the tangent fringe from the parabolic shape indicates actual tool path inaccuracies and/or tilt and focal misadjustment as shown in Figure $8(\mathrm{~b})$.

\section{Calculation of Offset}

Once the properly shaped fringe pattern is obtained, it is necessary to determine whether the tangent (arrowhead) fringe is a high or a low. This is accomplished by gently pushing the interferometer toward the mirror. If the fringes run outward from the zero fringe, the arrowhead fringe is high; if the fringes run toward the zero fringe, the tangent fringe is low. 


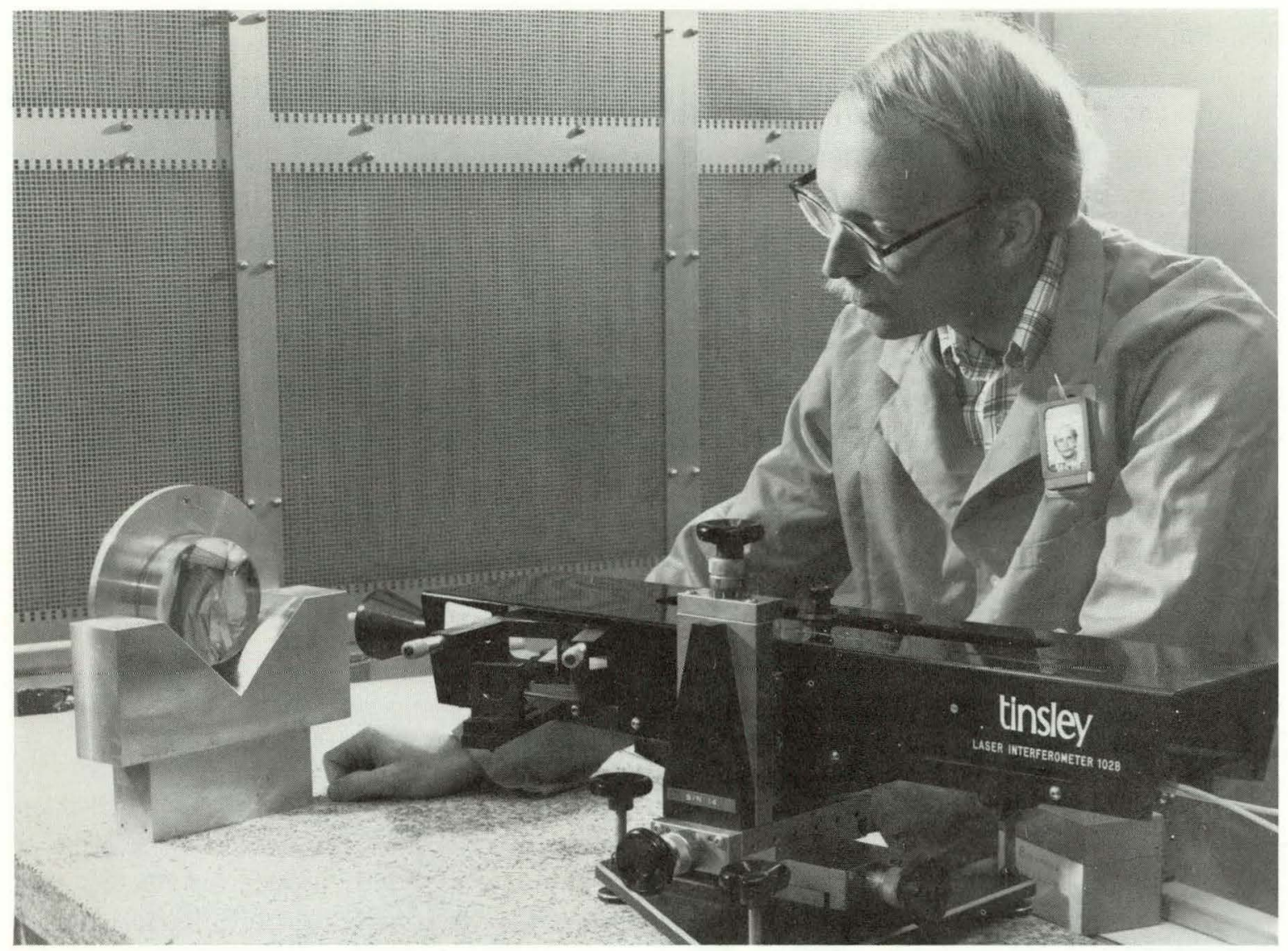

188237

Figure 7. INTERFEROMETER SETUP FOR MEASURING TOOL OFFSET ERROR.

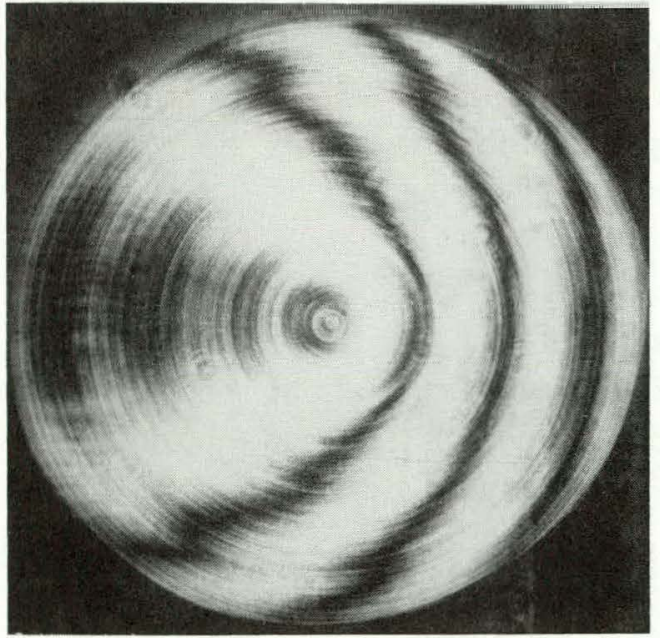

(a) Three fringes of offset (cone) error.

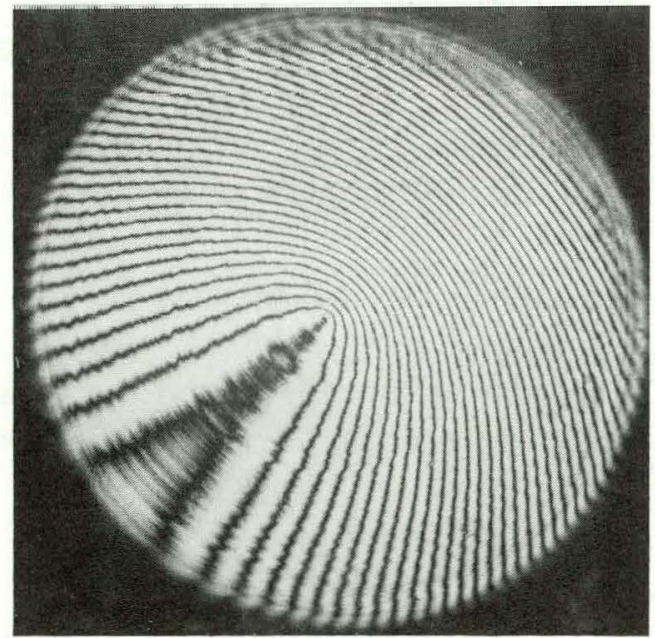

(b) Approximately 34 fringes of offset (cone) error.

Figure 8. INTERFEROGRAMS OF OFFSET ERROR IN TWO DIFFERENT PARTS. 
To calculate the magnitude of offset for an $\mathrm{f} / 2$ mirror, simply count the number of fringes, $K$, (starting at zero) and multiply by the wavelength of the laser source. The direction is determined after establishing the position (high or low) of the zero fringe. If it is low, the contour was started too close to the spindle centerline and should be moved away from the centerline in the amount of the calculated offset. If the zero fringe is high, the reverse procedure is required.

\section{Test Pieces and Fixturing}

Figure 9 shnu/s the alıminım test piere. This particular piece has a radius of curvature of $10 \mathrm{in}$ and an aperture of $4.5 \mathrm{in.}$ After being permanently bolted to a backing plate, Figure 10(a), three support pads on the backing plate were lapped, Figure $10(\mathrm{~b})$. In one application, this plate was fixed to a part to be machined. Possibly, it is more convenient-depending on the application-to mount the test mirror directly on the spindle and to wait until the inspection results are complete before mounting the actual mirror to be machined.

As in all diamond turning, every effort should be made to reduce all distortion induced by the fixture to a minimum. In actual observed practice, the astigmatism

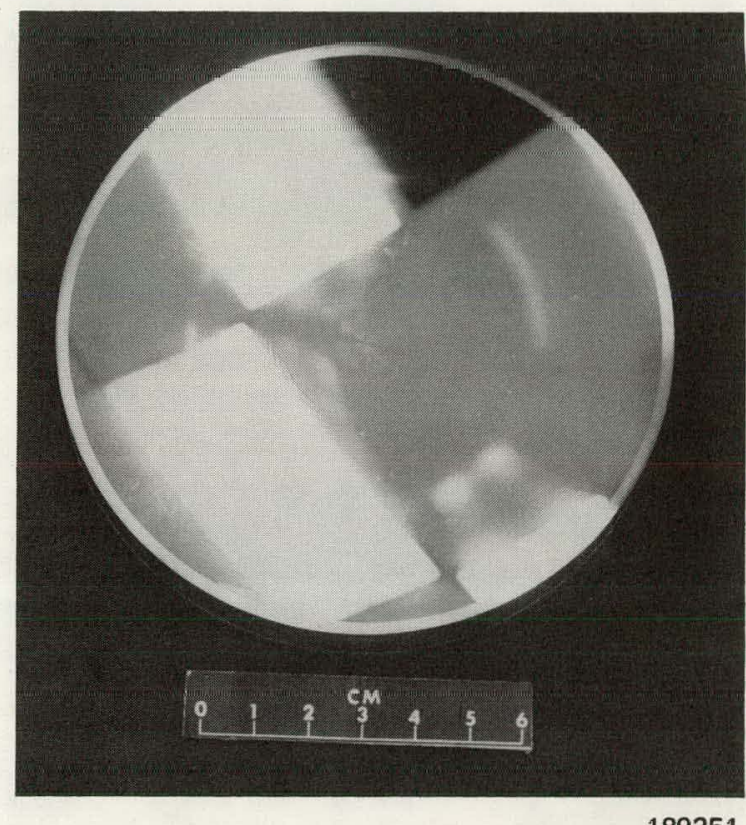

Figure 9. AN $1 / 2$ ALUMINUM TEST PIECE. that results from part distortion may be the limiting factor in resolving the tool offset error. If the machine configuration allows, the part may be checked on the machine to obtain the least possible distortion.

\section{Experimental Results}

Although six or more test parts had been machined and inspected, typical results are shown in Figure 11, Views (a) and (b). Figure 11(a) shows the results after initial machining. Tool setting for this initial machining was done by microscopically viewing the center of the rotating part. The accuracy with this method has been shown to be within \pm 0.0006 in of the center. Examination of the photographs of the interferogram revealed five fringes of cone error. Using the formula derived as shown in Figure 6, an offset of $135 \mu$ in in the overshoot direction was calculated. The starting point of the tool was moved by this amount, and the mirror was remachined. Figure 11 (b) shows the interferogram of the part after the second cut; notice that the surface contour is less than $\lambda / 2$ deviation ( $12 \mu \mathrm{in})$. 


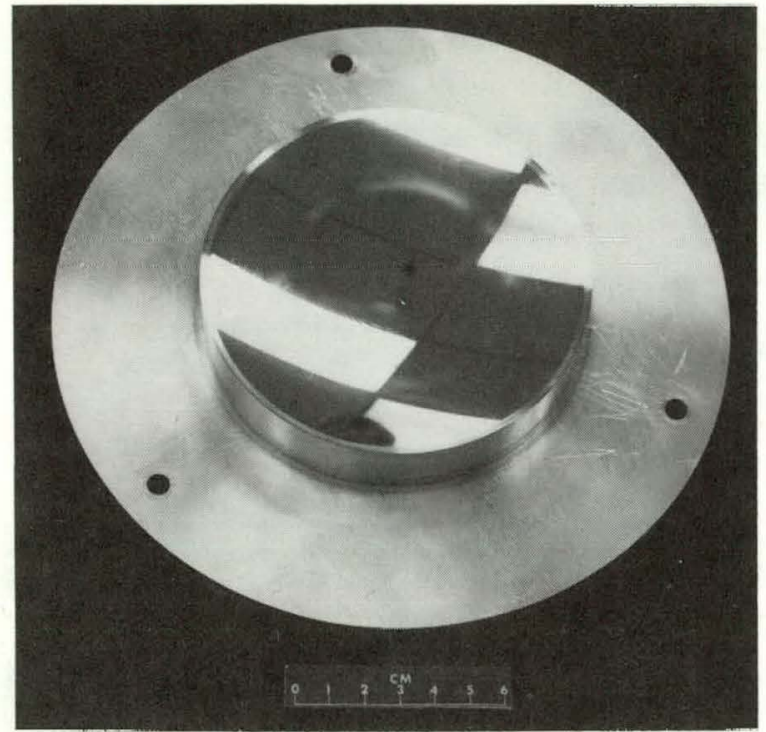

(a) Front view.

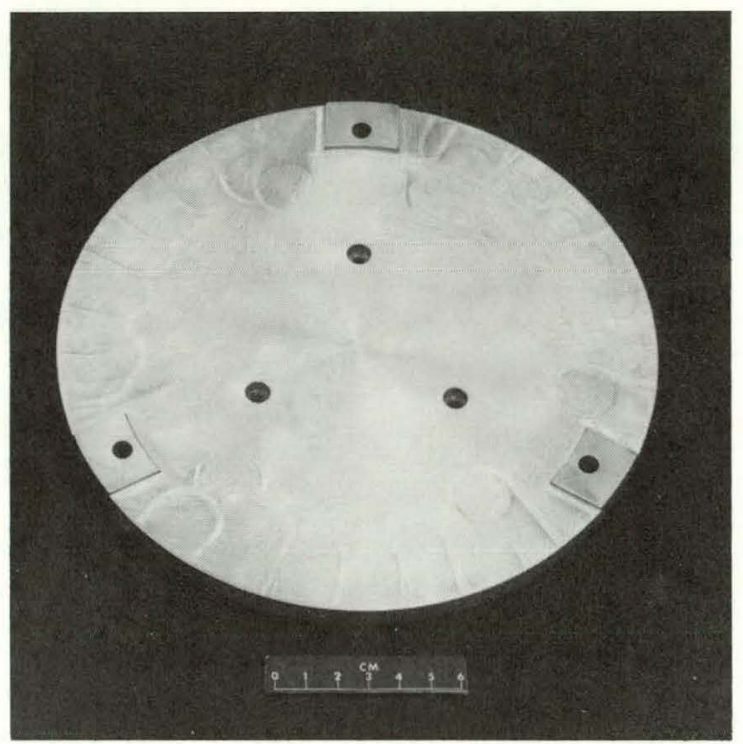

(b) Rear view.

189252

Figure 10. TEST PART ON SUPPORT PLATE.

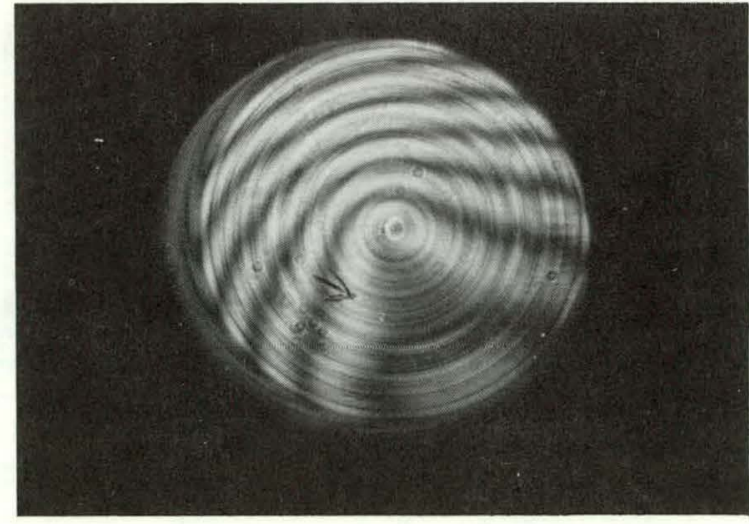

(a) Initial machining.

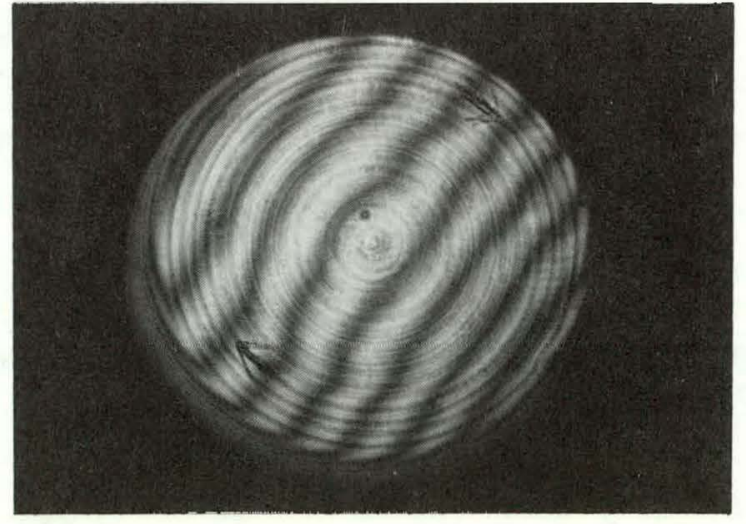

(b) Second machining.

Figure 11. INTEROGRAMS OF TEST MACHINING SEQUENCE FOR TOOL OFFSET CORRECTION. 


\section{CONCLUSIONS}

Experience thus far has indicated that the interferograms can be analyzed to within 1 to $1-1 / 2$ fringes of cone error given sufficient tool path accuracy of $\lambda / 4$ or better. This translates into 1 to $1-1 / 2$ wavelengths of lateral tool offset error (25 to $38 \mu \mathrm{in}$ for a helium-neon laser). Calculating the effect of offset on the part is somewhat involved. If the desired contour was on an $\mathrm{f} / 2$ spherical radius of a certain size with no deviation in that size allowed, the contour error would be $50 \%$ of the offset (Figure 12). However, if a best fit radius (three-point best fit) of a slightly different value can be accepted, the contour error induced is $<7 \%$ of the offset. The derivation of this error is shown in the Appendix. If a true least-squares best fit is applied, the error would be even less. If the offset is $40 \mu \mathrm{in}$, the three-point best fit will be $<3 \mu \mathrm{in}$. Also, for optics slower than $f / 2$, the contour error could be correspondingly less.

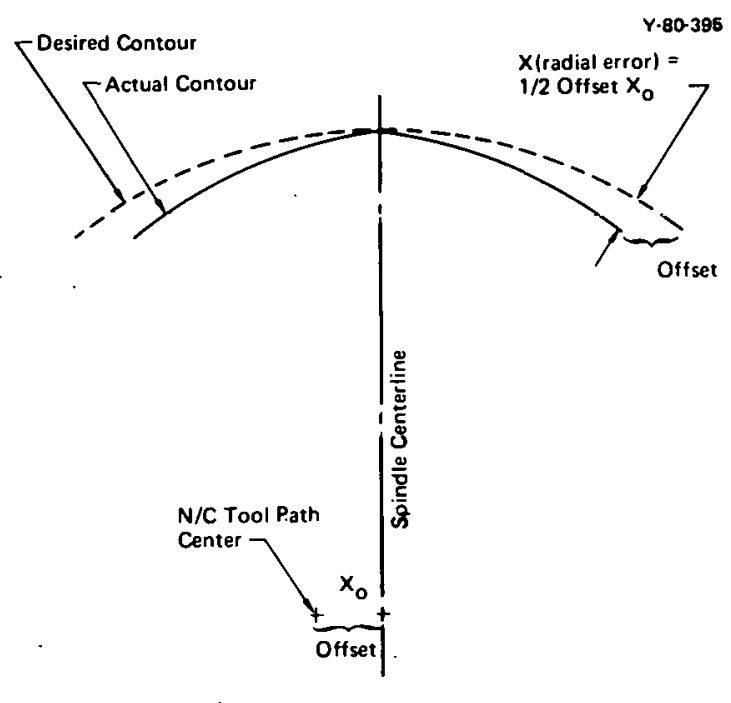

Figure 12. CONTOUR ERROR WITH NO RADIUS-OFCURVATURE SIZE CHANGE.

With a little experience, the optical test setup can be quickly and easily adjusted so that the number of fringes of linear cone can be readily determined. A best-fit analysis of this term is also available on John Loomis' fringe program. Tool setting by interferogram analysis has been completed (in the $\mathrm{Y}-12$ Plant) on a set of mirrors which were machined under a contract with $Y$-12. Also, a trial-and-error interferogram analysis $(b)$ for tool setting was done previously at a precision machine tool company in conjunction with $\mathrm{Y}-12$ Plant personnel. As diamond-turning technology grows, the ability to position the tool with respect to a spindle centerline will be an important part of the total process.

(b) A method in which the tool offset was not calculated. 


\section{REFERENCES}

1. Reedy, R. A.; Automatic Tool Setting for Numerically Controlled Machines, Y-1579; Union Carbide Corporation-Nuclear Division, Oak Ridge Y-12 Plant, Oak Ridge, Tennessee; May 22, 1967.

2. Asmanes, C.; A Spark-Gap Tool-Setting System, Y-1589; Union Carbide Corporation:Nuclear Division, Oak Ridge Y-12 Plant, Oak Ridge, Tennessee; September 20, 1967.

3. Henry, J. J.; An Ultrasonic-Acoustic Grinder Setting Station, Y-1935; Union Carbide Corporation-Nuclear Division, Oak Ridge Y-12 Plant, Oak Ridge, Tennessee; March 26 , 1974.

4. Sladky, R. E.; Handbook of Optical Testing Methods for Diamond-Turned Mirrors, Y/DA-8005; Union Carbide Corporation-Nuclear Division, Oak Ridge Y-12 Plant, Oak Ridge, Tennessee; October 19, 1978. 


\section{ACKNOWLEDGMENTS}

The authors wish to thank R. R. Williams of the $Y-12$ Plant Development Division and N. G. Young of the Y-12 Plant Fabrication Division for their assistance in designing and machining the fixtures and for machining the test parts. 


\section{APPENDIX .}

\section{DERIVATION OF THREE-POINT, BEST FIT, TRUE RADIUS}

Figure A-1 exemplifies the following equations:

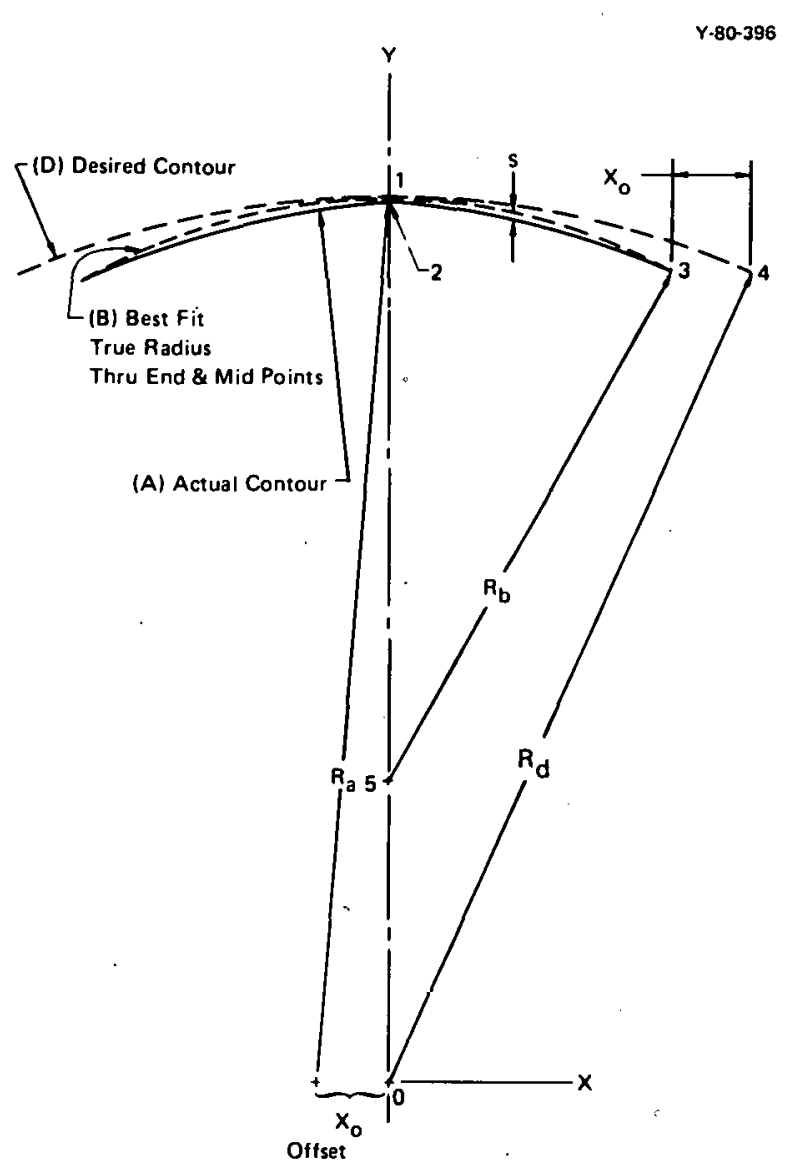

Figure A-1. CONTOUR ERROR WITH RADIUS-OFCURVATURE CHANGE.

where:

subscript $\mathrm{a}=$ actual curve,

subscript $b=$ true-radius, best fit curve to $a$, and subscript $d=$ desired curve.

$Y_{1}=R_{a}=R_{d}$

$X_{3}=X_{4}-X_{0}, Y_{3}=Y_{4}$

$R_{b}=$ distance between points 3 and $5=Y_{2}-Y_{5}$, and 
$Y_{2}$ is the $Y$ coordinate at an $X$ distance, $X_{0}$, from the $Y$-axis on the desired curve, $D$.

Then:

$$
Y_{2}=\sqrt{R_{a}^{2}-x_{o}^{2}}=\sqrt{R_{d}^{2}-x_{o}^{2}} .
$$

By Pythagoras: $R_{b}^{2}=\left(Y_{2}-Y_{5}\right)^{2}=\left(X_{3}-X_{5}\right)^{2}+\left(Y_{3}-Y_{5}\right)^{2}$,

and solving for $Y_{5}$ and substituting $X_{5}=0$ yields:

$$
Y_{5}=\frac{x_{3}^{2}+Y_{3}^{2}-Y_{2}^{2}}{2\left(Y_{3}-Y_{2}\right)}
$$

The equation of the best fit, true-radius curve is:

$$
x_{b}^{2}+\left(Y_{b}-Y_{5}\right)^{2}=R_{b}^{2}
$$

where: $R_{b}=Y_{2}-Y_{5}$.

The equation of the actual contour curve is:

$$
\left(x_{a}+x_{0}\right)^{2}+y_{a}^{2}=R_{a}^{2}
$$

where: $R_{a}$ is the actual radius of curvature.

With the equations of both curves determined, the distance between a point on the best fit curve and a point on the actual curve can be found by the distance formula:

$$
s=\sqrt{\left(X_{a}-X_{b}\right)^{2}+\left(Y_{a}-Y_{b}\right)^{2}} \text {. }
$$

For $f / 2$ or slower optics, the distance between the two curves can be approximated by the distance parallel to the $y$-axis:

$$
\begin{aligned}
& X_{a}=X_{b} \text {; therefore, } \\
& s=Y_{a}-Y_{b} .
\end{aligned}
$$

At the outer edge of an $f / 2$ optical piece, the error is less than $4 \%$.

By rearranging and combining Equations (A-2) and (A-3):

$$
Y_{b}=\left(\sqrt{R_{b}^{2}-X_{b}^{2}}\right)+\left(Y_{5}\right) \text {, and }
$$




$$
Y_{a}=\sqrt{R_{a}^{2}-\left(X_{a}+X_{0}\right)^{2}}
$$

if: $x_{b}=x_{a}$,

$$
Y_{b}-Y_{a}=\left(\sqrt{R_{b}^{2}-X_{a}^{2}}\right)-\left(\sqrt{R_{a}^{2}-\left(X_{a}+X_{0}\right)^{2}}\right)+\left(Y_{5}\right) .
$$

As an example, let:

$$
\begin{aligned}
& R_{d}=10.000 \text { in and } \\
& X_{0}=0.0001 \text { in . }
\end{aligned}
$$

Then:

$$
\begin{aligned}
& X_{4}=\frac{R_{d}}{4}=2.500 \text { for } f / 2 \text { optic, } \\
& Y_{4}=\sqrt{R_{d}^{2}-X_{4}^{2}}=9.682458=Y_{3}, \\
& X_{3}=X_{4}-X_{0}=2.4999 \text {, and } \\
& Y_{2}=10.0 \text { to the eighth decimal place. }
\end{aligned}
$$

By Equation (A-1):

$$
\begin{aligned}
& Y_{5}=\frac{X_{3}^{2}+Y_{3}^{2}-Y_{2}^{2}}{2\left(Y_{3}-Y_{2}\right)} \\
& Y_{5}=0.000798, \text { and } \\
& R_{b}=9.999202 .
\end{aligned}
$$

The maximum deviation should be near the midpoint of the distance outward from the center where:

$$
x_{a}=\frac{x_{4}}{2}=\frac{R_{d}}{8}=1.25 .
$$

Substituting into Equation (A-4):

$$
Y_{b}-Y_{a}=0.000006 \text { in. }
$$




\section{Distribution}

Bell Industries

Huff, J. L.

Department of Energy - Oak Ridge

Hickman, H. D.

Poteat, R. M.

Honeywell Electro-Optics - Lexington, Mass.

Johnson, F. E.

Lawrence Livermore National Laboratory

Arnuld, W. F.

Bryan, J. B.

Donaldson, R. R.

Los Alamos National Scientific Laboratory

Blevins, D. J.

Hoyt, H. C.

Munroe, J. L.

Reichelt, $W$.

Moore Special Tool Company - Bridgeport, Conn.

Hannah, P. R.

Naval Weapons Center - China Lake, Calif.

Decker, D. L.

National Bureau of Standards - Gaithersburg, Md.

Hocken, R.

Oak Ridge Gaseous Diffusion Plant

Armstrong, R. C.

Stief, S. S.

Wilcox, W. J., Jr.

Oak Ridge National Laboratory

Hopkins, C. C.

\section{Oak Ridge Y.12 Plant}

Barkman, W. E.

Casstevens, J. M.

Dodson, W. H./Googin, J. M.
Fraser, R. J.

Gerth, H. L.

Hurst, J. S.

Johnson, $E$.

Keith, A.

Kite, H. T.

Marcum, R. C.

Mills, J. M., Jr.

Pardue, R. M.

Rasnick, W. H. (15)

Robinson, S. C.

Sladky, R. E.

Steger, P. J.

Tunnell, H. A.

Whitten, L. G.

Yoder, R. C. (15)

$Y-12$ Central Files (master copy)

$Y-12$ Central Files (route copy)

$Y$-12 Central Files ( $Y$-12RC)

$Y-12$ Central Files (5)

Paducah Gaseous Diffusion Plant

Bewley, H. D.

Pneumo Precision - Keene, N. H.

Brehm, T. D.

Sandia National Laboratories - Livermore

Spencer, W. J.

Union Carbide Corporation - New York

Tinsley, S. W.

University of Arizona

Parks, R. E.

Wyant, J.

In addition. this report is distributed in accordance with the Category UC-38, Engineering and Equipment, as given in the Standard Distribution for Unclassified Scientific and Technical Reports, DOE/TIC-4500. 